\title{
COMPARISON OF THERMOECONOMIC COST CALCULATION FOR A BINARY GEOTHERMAL POWER PLANT
}

\author{
C. Yilmaz ${ }^{1, *}$
}

\begin{abstract}
This paper presents a comparison of the three thermoeconomic methodologies, SPECO (Specific exergy costing), MOPSA (Modified productive structure analysis) and Moran for an existing binary geothermal power plant in western Turkey. Exergy and exergoeconomic analyses of the Dora II binary geothermal power plant with $9543 \mathrm{~kW}$ net power output is carried out by using actual plant data to evaluate plant performances and thermoeconomic costs. The objective of the study is to perform the advantages and disadvantages of the presented thermoeconomic methods with respect to the one other using a binary geothermal plant data. The presented thermoeconomic methodologies are used to reveal and compare the cost flows and products interactions between the system components. The overall energy and exergy efficiencies of the plant are calculated to be $47.3 \%$ and $13.5 \%$. The unit exergetic costs of electricity are calculated to be $0.0436 \$ / \mathrm{kWh}$ for MOPSA method, $0.0367 \$ / \mathrm{kWh}$ for SPECO method and $0.0355 \$ / \mathrm{kWh}$ for MORAN method, respectively.
\end{abstract}

\section{Keywords: Geothermal Power, Thermoeconomic Analysis, SPECO, MOPSA, Moran Methods}

\section{INTRODUCTION}

Energy is the great deals of the phenomena in the world and it is a very important tool for the sustainability of life. Because we use it in every single thing we do. Especially developed and developing countries are required too much needs. Electricity is the most efficient and useful forms of the energy. Therefore, different kinds of resources and methods are used in energy production. In addition, many explorations and investigations are being to solve energy requirements. Environmental disasters and recent progress caused by the use of fossil fuels that have led us directly to the use of renewable energy sources for energy productions. Harmful effects of the environmental pollution on living and human health are increasing day by day. For that reason, there is a restriction to the use of the fossil fuels for the use of energy on a country basis. Renewable energy power production is attractive and feasible way to solve for the environmental pollutants and health problems [1]. Main renewable energy sources include solar, wind, hydropower, geothermal and biomass. Hydroelectric, geothermal and wind power generation are able to compete with fossil fuel based on electricity generation economically but solar electricity is still expensive. However, steady decrease in solar electricity cost and government incentives can help wider use of solar electricity. Biomass, solar, and geothermal electricity generation are also expected to increase in the coming years [2].

Among renewable sources, geothermal energy has significant potential in electricity production for Turkey. Geothermal energy is the water thermal absorbed energy by the ground within the earth interior energy. It is a renewable energy resource because heat is continuously transferred from within the earth to the water recycled by rainfall or reinjected back to the ground after use. Geothermal energy conversion is one of the most mature renewable energy technologies. Geothermal energy is mostly used for electricity production and heating. Today, the most common method is the binary geothermal power plant that allows electricity generation from low grade energy sources [3]. As it is considered to electricity production assisted by the geothermal energy. Because geothermal energy is the most popular and common renewable energy source in Turkey. Turkey is a developing country, so energy requirements are too high for industry and commercial applications. In particular, the use of renewable and domestic energy sources will be very important to solve our external dependency on the energy requirements. Turkey geothermal resources are mainly composed of low grade energy sources. But this is not a disadvantage with the progress of new technology. Binary systems that are developed with low boiling point as a working fluids makes possible to produce of electricity. Thus, electricity can be produced from low temperature geothermal water. A binary plant in Alaska uses a geothermal resource at $57^{\circ} \mathrm{C}$ [4]. These plants operate on a Rankine cycle with binary working fluid (isobutene, pentane, isopentane, R-114, etc.) that has a low 
boiling temperature. The unit electricity cost that can be produced from geothermal resources is $5-7 \$ / \mathrm{kWh}$ for power plant capacity less than $5 \mathrm{MW}$. The electricity production cost is about $4-7 \$ / \mathrm{kWh}$ for the plant capacity of 5-30 MW. Finally, electricity production cost is about $2.5-5 \$ / \mathrm{kWh}$ for the geothermal power plants larger than $30 \mathrm{MW}$ capacity [5].

Although, there are large numbers of studies in solar, wind, and hydropower energies for electricity production, limited number of studies exists on using geothermal energy. Next it is provided an overview of some of the more relevant studies in literature. Ganjehsarabi et al. [6] has been conducted an exergetic performance analysis of the Dora II geothermal power. They are evaluated the overall energetic and exergetic efficiencies of the plant to be $10.7 \%$ and $29.6 \%$, respectively. Zare [7] has investigated and compared the performance of three organic Rankine cycles (ORC) for binary geothermal plants. He is evaluated to three organic Rankine cycles (ORC) configurations for the plants that considered product cost optimization and proper model selection. Ozgener and Yildirim [8] have conducted a review on the thermodynamic and exergoeconomic analysis of geothermal plants. Exergoeconomic analysis of Dora I and Dora II are calculated by them. They are evaluated simple thermodynamic and exergoeconomic analysis of the plant. Especially comparisons of the two plant results are evaluated by simultaneously. Rašković et al. [9] have conducted a case study on the performance analysis of electricity generation by medium temperature geothermal resources. Their results of the study showed that the plant design based on the Rankine cycle has a higher efficiency and lowest cost of equipment and also, this type of plant is more feasible for the future geothermal plants in low grade geothermal resources area. Coskun et al. [10] has performed a modified exergoeconomic model was proposed for the analysis of geothermal power plant and special case application that applied to the Tuzla geothermal plant. Their study is the first exergy cost calculation for Turkey geothermal plants. Besides of these, the existing electricity power productions of geothermal resources areas are considered for Turkey. They can be listed as follows: DenizliKizildere $\left(242^{\circ} \mathrm{C}\right)$, Aydin-Germencik $\left(232^{\circ} \mathrm{C}\right)$, Canakkale-Tuzla $\left(173^{\circ} \mathrm{C}\right)$, Aydin-Salavatli $\left(171^{\circ} \mathrm{C}\right)$, AydinYilmazkoy $\left(165^{\circ} \mathrm{C}\right)$, Kutahya-Simav $\left(162^{\circ} \mathrm{C}\right)$, Manisa-Salihli $\left(155^{\circ} \mathrm{C}\right)$, Izmir-Seferihisar $\left(153^{\circ} \mathrm{C}\right)$, and IzmirBalcova $\left(126^{\circ} \mathrm{C}\right)$ (Erdogdu, 2009). The current installed geothermal power plant capacity is $992 \mathrm{MW}$ with recent developments and government incentives for Turkey [11].

The thermodynamic analysis of the plant has been carried out and performance values have been conducted. There is no cost analysis study that was found for the system in the literature. It will be performed a study that includes the thermoeconomic analysis of the Dora II geothermal binary plant. The unit cost of electricity produced by using different thermoeconomic analysis methods is considered. The plant is analyzed and the obtaining cost results of thermoecenomic methods are compared by each other. Thermoeconomic cost analysis methods are developed by Lazzaretto and Tsatsaronis [12] that are specific exergy costing approach.

According to the specific exergy costing (SPECO) approach [13], fuels and products are defined systematically by registering exergy additions to and removals from each material and energy stream. This method consist of three main steps (1) identification of exergy streams, (2) definition of fuel and product for each system for each system components, (3) cost balance equations. This method has been largely and successfully used and applied to the thermal systems by the researchers in the area of thermoeconomics. Also, SPECO is the most real and applicable to the thermal system and easy and speed results can be obtained by the way. This approach is more flexible than other, allows engineers to actively participate in the cost assigning process and leads to results that are much closer to anticipated values. The approach is the simplest and most general approach among all versions of the exergoeconomic method presented in the study.

Modified productive structure exergoeconomic cost analysis (MOPSA) approach is the first proposed by Kwak et al.[14]. The method is based on the exergy costing approach without flow stream cost calculation. In the MOPSA method, a cost balance equation is obtained by assigning unit exergy cost to each disaggregated exergy in the stream at any state. This method is considered physical and chemical parameters of the flow of each stream. The calculation of exergetic cost is more complicated as a result of this method. So, this method will give more accurate results for chemical process system plants. There is no need much detail of electricity production for the thermal systems.

In the Moran method, production cost deepens on fuel cost and exergetic efficiency of the plant and is affected by the ratio of the monetary flow rate of non-fuel items to the monetary flow rate of fuel items. In this method, it is not easy task to calculate the production costs if the plant produces multiple products or has multiple input fuels. Overall system as can be seen to a unique that assumption to produce unit product cost results approach is expressed by Moran method [15]. 
In this study presents a comparison of the three thermoeconomic approaches that applied for the existing binary geothermal power plant of Dora II. The geothermal plant of Dora II contains two binary unit systems that operate simultaneously. The unit cost electricity production from geothermal water is investigated by using the three well-known exergoeconomic methods. The first one of them is SPECO (Specific exergy costing) method, the second one is MOPSA (Modified productive structure analysis) method, and third one of them is Moran method. The plant has a total power capacity of $9.5 \mathrm{MW}$ and installed in Aydin city of Turkey. The developed of the computer aided thermeoconomic model based on the three approaches are used to reveal and compare the cost flows between system components. The novelty of this study is the cost results calculations and comparisons by applying different thermoeconomic methods and also can be expressed as i) to performed thermodynamic analysis of the plant, ii) to evaluate system components and streams using the thermoeconomic analysis, iii) to conduct the exergy cost balance equations for each component and to evaluate the three possible thermoeconomic methods results of the plant and iv) to exhibit the advantages and disadvantages of the thermoeconomic methodologies with respect to the other approaches an existing binary geothermal power plant.

\section{SYSTEM DESCRIPTION AND WORKING PRINCIPLE}

The geothermal power plant Dora II presented in Figure 1 is an existing binary power plant which is located in the western Turkey in the city of Aydin and started to produce power in 2010. Dora II geothermal power plant considered has a power capacity of $9540 \mathrm{~kW}$. The operating system is an integrated two level (ITLU) double conversion system. ITLU system is a simple Rankine cycle in which the boiling of the working fluid occurs at the two pressure levels. This operating system provides better utilization efficiency and allows geothermal water is to be cooled at lower temperature before reinjected to the ground that provides more heat absorption.

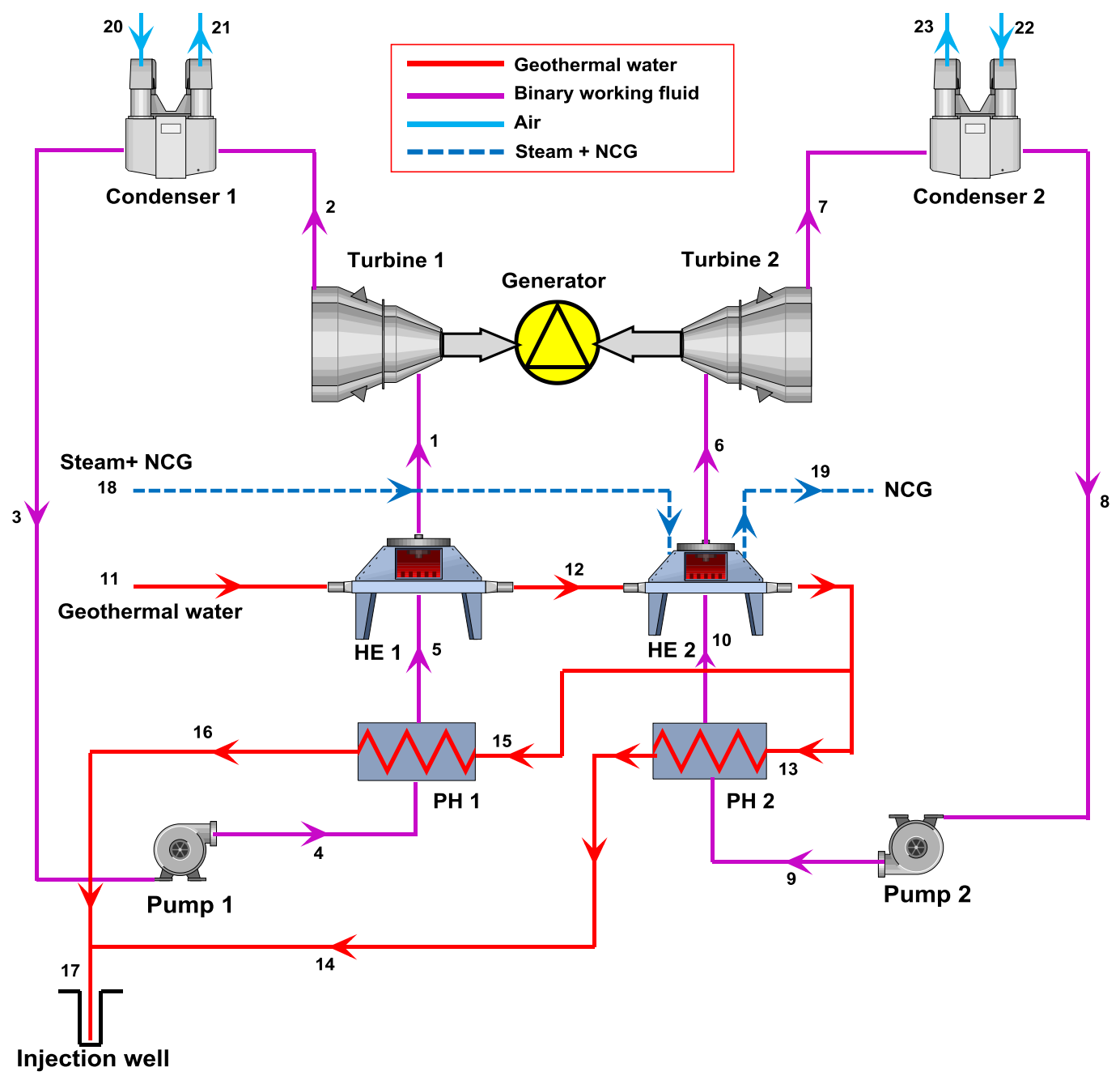

Figure 1. Representative configuration of Dora-II binary geothermal power plant [16] 
Dora II binary power plant uses the effective geothermal water temperature $160.1^{\circ} \mathrm{C}$ as the heat source of energy input for the electricity generation. Dora II plant has the geothermal water characteristic of liquid dominated resources at relatively low temperatures. The cycle operates on the combined two stages Rankine cycle with $\mathrm{n}$ pentane as the working fluid that has a low boiling temperature. Geothermal water energy is transferred to the cycle by the binary heat exchangers in which geothermal water enters at $160.1{ }^{\circ} \mathrm{C}$ at a rate of $168.9 \mathrm{~kg} / \mathrm{s}$ and leaves $62{ }^{\circ} \mathrm{C} . \mathrm{n}$ - Pentane enters the binary turbines at $1650 \mathrm{kPa}$ in high level and $720 \mathrm{kPa}$ in low level unit. The highest temperatures of $\mathrm{n}$ - pentane at the inlet state of the turbines in the cycles are $145^{\circ} \mathrm{C}$ and $105^{\circ} \mathrm{C} . \mathrm{n}$ - Pentane is condensed in an air cooled condensers and pumped to the heat exchangers pressures. The pumps and turbines isentropic efficiencies are taken to be \%85. The geothermal water passes through a series of binary heat exchangers where energy is transferred to the binary working fluid of $n$ - Pentane before the geothermal water is reinjected back to the ground at $62^{\circ} \mathrm{C}$. The binary working fluid of $\mathrm{n}$ - Pentane is condensed through air cooled condenser, so there is no need to consumption of fresh water. And also, the schematic of the plant with state numbers and equipments are given Fig.1. These thermodynamic data are almost real experimental values of the plant [16]. The $\mathrm{n}$ - Pentane that has low boiling point temperature is vaporized to spin the turbines for production of electricity which connected to a power generator. All geothermal plants operating on the reservoir area used steam that is accompanied by significant amount of non condensable gases (NGC). When the concentration exceeded about 5\% by weight of steam, two level cycle model can be used [11].

The production units are consisted of the closed loop cycles in themselves due to the totally reinjected of the geothermal water back to the ground. Thus, both the sustainability of the resources and bad environmental effects are eliminated. This system operating type as engineering that is a useful example for geothermal resources to be renewable and suitable.

\section{THERMODYNAMIC ANALYSIS OF THE PLANT}

The plant and components are assumed to be a steady- state flow process in thermodynamically and also, use the control volume that is used in the calculation of the plant. Mass, energy and exergy balance equations for the control volume at steady state with neglecting other forms of energy requirements can be written as follows [17].

$$
\begin{gathered}
\sum \dot{m}_{i}=\sum \dot{m}_{e} \\
\dot{Q}-\dot{W}=\sum \dot{m}_{e} h_{e}-\sum \dot{m}_{i} h_{i} \\
\dot{E} x_{\text {heat }}-\dot{W}=\sum \dot{m}_{e} e x_{e}-\sum \dot{m}_{i} e x_{i}+\dot{E} x_{\text {dest }}
\end{gathered}
$$

where $\dot{Q}$ and $\dot{W}$ are net input and work output, the denotations $i$ and $e$ indices represent inlet and exit states, $\dot{m}$ mass flow rate, $h$ specific enthalpy, ex specific exergy flow, $\dot{E} x_{\text {dest }}$ exergy destruction rate, and $\dot{E} x_{\text {heat }}$ the exergy rate with heat transfer at temperature $T$, which is given by

$$
\dot{E} x_{\text {heat }}=\sum\left(1-\frac{T_{0}}{T}\right) \dot{Q}
$$

The specific exergy rate is given by

$$
e x=\left(h-h_{0}\right)-T_{0}\left(s-s_{0}\right)
$$

where $s$ is the specific entropy and the indices 0 denotes the dead state. 
The thermal efficiency of a geothermal plant can be defined as a measure of how well the geothermal water energy is converted to the electricity work and also, same way exergy efficiency of the plant can be defined. Thermodynamic first and second low efficiency of the plants can be written as

$$
\begin{gathered}
\eta=\frac{\dot{W}_{\text {net,geo }}}{\dot{Q}_{\text {geo,in }}}=\frac{\dot{W}_{\text {turbines }}-\dot{W}_{\text {parasitic }}}{\dot{m}_{\text {geo }}\left(h_{\text {geo }}-h_{0}\right)} \\
\varepsilon=\frac{\dot{W}_{\text {net }, \text { geo }}}{\dot{E} x_{\text {geo }, \text { in }}}=\frac{\dot{W}_{\text {turbines }}-\dot{W}_{\text {parasitic }}}{\dot{m}_{g e o}\left(h_{\text {geo }}-h_{0}-T_{0}\left(s_{\text {geo }}-s_{0}\right)\right)}
\end{gathered}
$$

where $\dot{W}_{n e t, g e o}$ is the net power output from the plant, $\dot{Q}_{g e o, \text { in }}$ is the net energy input to the plant and $\dot{E} x_{g e o, \text { in }}$ is the exergy input to the plant from geothermal water. Here, $\dot{m}_{g e o}$ is the mass flow rate of geothermal water and "geo" index denotes the geothermal water specific enthalpy and entropy values and " $O$ " index denotes the environmental dead states specific enthalpy and entropy values. $\dot{W}_{\text {parasitic }}$ is the parasitic work used in the plant for various internal and external uses. The parasitic work is mainly comprised of fan work consumption in the air-cooled condenser. It is assumed that about $\% 20$ of net work output is used satisfy the parasitic work requirements [17].

\begin{tabular}{|c|c|c|c|c|c|c|c|c|}
\hline State & Fluid & $P(\mathbf{k P a})$ & $T\left({ }^{\circ} \mathrm{C}\right)$ & $\dot{m}(\mathrm{~kg} / \mathrm{s})$ & $h(\mathrm{~kJ} / \mathrm{kg})$ & $s\left(\mathrm{~kJ} / \mathrm{kg}^{\circ} \mathrm{C}\right)$ & $e x(\mathbf{k J} / \mathbf{k g})$ & $\dot{E} x(\mathbf{k W})$ \\
\hline 0 & Geothermal water & 84 & 14 & - & 58.87 & 0.2099 & - & - \\
\hline $0^{\prime}$ & n-pentane & 84 & 14 & - & -374.6 & -1.774 & - & - \\
\hline $0 "$ & Air & 84 & 14 & - & 287.5 & 5.658 & - & - \\
\hline 1 & n-pentane & 1650 & 145 & 76.73 & 179.1 & -0.3018 & 131 & 10054 \\
\hline 2 & n-pentane & 120 & 80 & 76.73 & 93.67 & -0.2596 & 33.48 & 2569 \\
\hline 3 & n-pentane & 120 & 31.5 & 76.73 & -335.2 & -1.641 & 1.255 & 96.32 \\
\hline 4 & n-pentane & 1650 & 32.4 & 76.73 & -332.1 & -1.639 & 3.807 & 292.1 \\
\hline 5 & n-pentane & 1650 & 117.4 & 76.73 & -114.1 & -1.012 & 41.87 & 3213 \\
\hline 6 & n-pentane & 720 & 105 & 70.31 & 121.9 & -0.3723 & 94.07 & 6615 \\
\hline 7 & n-pentane & 100 & 61.5 & 70.31 & 59.14 & -0.3397 & 21.93 & 1542 \\
\hline 8 & n-pentane & 100 & 26 & 70.31 & -347.9 & -1.682 & 0.6102 & 42.91 \\
\hline 9 & n-pentane & 720 & 26.4 & 70.31 & -346.5 & -1.682 & 1.631 & 114.7 \\
\hline 10 & n-pentane & 720 & 100 & 70.31 & -88.11 & -0.935 & 45.64 & 3209 \\
\hline 11 & Geothermal water & 620 & 160.1 & 168.9 & 676 & 1.944 & 119.3 & 20154 \\
\hline 12 & Geothermal water & 620 & 130 & 168.9 & 546.6 & 1.634 & 78.81 & 13312 \\
\hline 13 & Geothermal water & 620 & 110 & 84.45 & 461.8 & 1.418 & 55.94 & 4725 \\
\hline 14 & Geothermal water & 620 & 60 & 84.45 & 251.7 & 0.831 & 14.55 & 1229 \\
\hline 15 & Geothermal water & 620 & 110 & 84.45 & 461.8 & 1.418 & 55.94 & 4725 \\
\hline 16 & Geothermal water & 620 & 64 & 84.45 & 268.4 & 0.8809 & 16.95 & 1431 \\
\hline 17 & Geothermal water & 620 & 62 & 168.9 & 260.1 & 0.856 & 15.73 & 2657 \\
\hline 18 & NCG & 620 & 160.1 & 5.085 & 2758 & 6.748 & 821.3 & 4177 \\
\hline 19 & NCG & 620 & 111.8 & 5.085 & 2707 & 7.118 & 761.67 & 293.7 \\
\hline 20 & Air & 101.3 & 14 & 2114 & 287.5 & 5.658 & 0 & 0 \\
\hline 21 & Air & 101.3 & 29.5 & 2114 & 303.1 & 5.71 & 0.4008 & 847.2 \\
\hline 22 & Air & 101.3 & 14 & 2191 & 287.5 & 5.658 & 0 & 0 \\
\hline 23 & Air & 101.3 & 27 & 2191 & 300.6 & 5.702 & 0.2867 & 606 \\
\hline
\end{tabular}

Table 1. Thermodynamic analysis results of the plant 
Under these operating conditions, obtaining results are summarized and explained in Table 1. Each states of system are solved by simultaneously and denoted energy and exergy rates. Plant components energy and exergy values are calculated by fuel-product approach. So that can be supplied to define the exergy losses part of the system. These loses are effect by the system flow costs. Exergy cost methodologies are directly related to the unit state exergy vales of each stream of the system. Exergetic cost values are assigned for each stream of flow chart of the system. All flow exergetic cost possibilities are solved by simultaneously that can be extracted unknown flow cost parameters. Some cost values are assumed before the system simulated in the computer environment. So these values real literature operations values for that reason that are assumed by the open literatures. Thermodynamic energy and exergy analyses are very important thing for that reason through the thermoeconomic analysis. Due to the thermodynamic analysis is the key of primary carrier of thermoeconomic calculation of the system. Thermodynamic analysis results are obtained under these real operating conditions of the modeled system that are given in Table 1.

\section{THERMOECONOMIC ANALYSIS OF THE PLANT}

A cost balance for a system is usually performed at a steady state for each of the system equipment as a control volume assumption that can be denoted for balance equation by [18]

$$
\sum_{\text {in }} \dot{C}_{k, \text { in }}+\dot{Z}_{k}^{T}+\dot{C}_{k}^{Q}=\sum_{\text {out }} \dot{C}_{k, \text { out }}+\dot{C}_{k}^{W}
$$

Here;

$$
\dot{C}=c \times \dot{E} x
$$

$c$ is the associated average cost per unit of exergy stream in $\$ / \mathrm{kJ}, \dot{C}$ is the stream associated with the corresponding exergy stream, $\dot{C}_{k}^{Q}$ and $\dot{C}_{k}^{W}$ are the cost rates associated with heat and power from the components in $\$ / \mathrm{h}$, respectively. The term of $\dot{Z}_{k}^{T}$ is the summation costs rate for the each equipment investment cost and also, operating and maintenance costs in hourly levelized of $\$ / \mathrm{h}$. Here are personalized recommendations based on economic latest evaluated values in thermoeconomic analysis. The total value of equipment levelized cost value is expressed as [18]

$$
\dot{Z}_{k}^{T}=\dot{Z}_{k}^{I C}+\dot{Z}_{k}^{O M C}
$$

The calculation of values of the equation parameters can be calculated to use by levelized cost method. These are given as follows [18].

The present worth factor for a particular plant equipment can be written as

$$
P W_{k}=P E C_{k}-S_{k} \times P W F
$$

The salvage value:

$$
S_{k}=S V \times P E C_{k}
$$

The present worth factor (PWF)

$$
P W F=\frac{1}{(1+i)^{n}}
$$


Annual capital investment cost of the component $\left(C_{\mathrm{k}}\right)$

$$
C_{k}=P W_{k} \times C R F
$$

Capital recovery factor (CRF)

$$
C R F=\frac{i(1+i)^{n}}{(1+i)^{n}-1}
$$

Annualized equipment cost of the plant

$$
\dot{Z}_{k}^{I C}=\frac{C_{k}}{\tau}
$$

System hourly operation and maintenance cost of the each component in the plant is determined from the overall system annual operation and maintenance cost

$$
\dot{Z}_{k}^{O M C}=\frac{O M C}{\tau} \frac{P E C_{k}}{\sum P E C}
$$

where $\tau$ is the annual operation time of the plant in hourly, OMC is the yearly operation and maintenance cost of the plant. The economic life period of the plant $n$ is assumed to be 20 years and yearly interest rate, $i$ of the plant investment is taken to be $\% 7$ for the plant. $S_{\mathrm{k}}$ is the salvage value of the each equipment of the plant that can be assumed to be a $S V \% 20$ of the purchase equipment cost. The sale value of the system at the end of its service lifetime is called salvage or scrap value [19].

\section{THERMOECONOMIC COST RELATIONS}

In the cost formation process of an engineering system, many different approaches have been used to analyze for different engineering applications. These are classified and selected to the using areas. Because each application has unique features that allow it to achieve appropriate results, depending on its research area. For energy systems applications, thermodynamic based exergoeconomic methods would be more appropriate. Thermodynamically based cost assessment has become a challenge for feasibility studies. According to the results of the best appropriate models and the best working conditions are determined. Accordingly, the most common methods applied in the literature for energy systems are considered for the investigation. In this section the brief information on SPECO, MOPSA and Moran methods is given to obtain the exergy based cost equations for the existing binary geothermal power plant.

\section{Specific Exergy Costing (SPECO) Method}

The SPECO method is based on the cost association of all flows in the system depending on the exergy analysis. This method is fallowing procedures as: (i) definition and assignment of exergy streams of each state of the plant, (ii) the fuel and the product are identified for each component of the system and (iii) equations of the cost assignments. In the cost of exergy, each exergy flow is associated with a cost value. Exergy transfers by the entering and exiting streams of the plant and by power and heat transfer rates can expressed as [13]

$$
\begin{aligned}
& \dot{C}_{i}=c_{i} \dot{E} x_{i}=c_{i}\left(\dot{m}_{i} e_{i}\right) \\
& \dot{C}_{e}=c_{e} \dot{E} x_{e}=c_{e}\left(\dot{m}_{e} e_{e}\right) \\
& \dot{C}_{w}=c_{w} \dot{W}
\end{aligned}
$$




$$
\dot{C}_{q}=c_{q} \dot{E} x_{q}
$$

Accordingly, for a component receiving heat transfer and generating power, it may be written as

$$
\sum_{e}\left(c_{e} \dot{E} x_{e}\right)_{k}+c_{w, k} \dot{W}_{k}=c_{q, k} \dot{E} x_{q, k}+\sum_{i}\left(c_{i} \dot{E} x_{i}\right)_{k}+\dot{Z}_{k}^{T}+\sum_{i}\left(c_{i} E x_{i}\right)
$$

where $c_{i}, c_{e}, c_{w}$ and $c_{q}$ denote average costs per unit of exergy in dollars per gigajoule (\$/GJ).

\section{Modified Productive Structure Analysis (MOPSA)}

In this method, the thermomechanical exergy stream may be decomposed into mechanical and thermal components of exergy as [14]

$$
\dot{E} x_{i}^{m}-\dot{E} x_{j}^{m}=\left(\dot{E} x_{i}^{T}-\dot{E} x_{j}^{T}\right)+\left(\dot{E} x_{i}^{P}-\dot{E} x_{j}^{p}\right)
$$

where the subscripts $i$ and $j$ denote, respectively, exergy flow streams entering or leaving the plant component.

The thermal component of the exergy stream is given as:

$$
\dot{E} x_{i}^{T}=m\left[-\int_{T_{i}}^{T_{0}} \frac{\left(T-T_{0}\right)}{T} d h\right]
$$

With decomposition of an exergy stream defined in Equation 23, the exergy balance may be written as follows

$$
\begin{aligned}
& \dot{E} x^{C H E}+\dot{E} x^{B Q}+\left(\sum_{\text {inlet }} \dot{E} x_{i}^{T}-\sum_{\text {outlet }} \dot{E} x_{j}^{T}\right)+\left(\sum_{\text {inlet }} \dot{E} x_{i}^{P}-\sum_{\text {outlet }} \dot{E} x_{j}^{P}\right) \\
& +T_{0}\left(\sum_{\text {inlet }} \dot{S}_{i}-\sum_{\text {outlet }} \dot{S}_{j}\right)=\dot{E} x^{W}
\end{aligned}
$$

The fifth term in the Equation 24 represents the rate of entropy loss, and may be referred to as negentropy [14]. The term $\dot{E} x^{C H E}$ in Equation 24 denotes the rate of exergy flow of fuel in the plant. Assigning unit exergy cost to each decomposed exergy in the stream, the cost-balance equation corresponding to the exergy-balance equation given in Equation 24 may be written as

$$
\begin{aligned}
& \dot{E} x^{C H E} C_{0}+\dot{E} x^{B Q} C_{B Q}+\left(\sum_{\text {inlet }} \dot{E} x_{i}^{T}-\sum_{\text {outlet }} \dot{E} x_{j}^{T}\right) C_{T}+\left(\sum_{\text {inlet }} \dot{E} x_{i}^{P}-\sum_{\text {outlet }} \dot{E} x_{j}^{P}\right) C_{P} \\
& +T_{0}\left(\sum_{\text {inlet }} \dot{S}_{i}-\sum_{\text {outlet }} \dot{S}_{j}\right) C_{S}+\dot{Z}_{k}^{T}=\dot{E} x^{W} C_{W}
\end{aligned}
$$

The term $\dot{Z}_{k}^{T}$ includes all financial charges associated with owning and operating the $k_{t h}$ plant component. Equations 24 and 25 are two basic relations used in the MOPSA method for exergy costing of products. 


\section{Unit System of One Product (Moran) Method}

In this method, the system has a single input that is a fuel and a single output that is electricity. In this approach, the cost of fuel consumed at any time interval is considered to be an important part of the total cost for that period. For such a system, it is convenient to express the annual cost of the product as the sum of fuel cost, plant installation cost and operating and maintenance cost. The cost of the product due to the second law (exergy) efficiency for the plant can be described as follows [15],

$$
c_{\text {electricity }}=\frac{c_{\text {geo }}}{\eta_{e x}}\left(1+\frac{\sum Z_{k}^{T}}{c_{\text {geo }} \dot{E} x_{i n}}\right)
$$

In the geothermal power plant the geothermal water is assumed as a fuel. The direct cost of the geothermal exploration work ( $C_{\text {geothermal }}=2,532,221 \$$ ), can be estimated based on the Aydın-Salavatl geothermal power plant zones. According to the World Bank Group (2004), the direct cost for typical low-temperature geothermal resource exploration work varies between 400 and 1,000 $\$ / \mathrm{kW}$. It includes a preliminary geological survey based on geological photos or a remote sensing scan, detailed geological and/or geochemical surveys, geophysical surveying and/or shallow thermal gradient well drilling, drilling of test wells and reservoir modeling [20]. Thus, the levelized specific cost of the geothermal water, $c_{g e o}(\$ / \mathrm{kg})$, is determined as,

$$
c_{\text {geo }}=\frac{C_{\text {geothermal }} \times C R F}{\dot{m}_{g e o} \times t_{o p}}
$$

where CRF is the capital recovery factor, top is the operating time in a year and, is the flow rate of geothermal water in the plant.

\section{RESULTS AND DISCUSSION}

Using low temperature resources, geothermal power plants generally have low energy efficiencies. Consequently, the energy efficiency of the binary plant is calculated to be $13.5 \%$ based on the energy input to the n pentane Rankine cycles, according to the states at 11 and 17.this means that more than $80 \%$ of the energy of the geothermal water in the reservoir is discarded as waste heat. Exergy rate input in the plant is calculated to be $20,150 \mathrm{~kW}$ by approximation of exergy transferred from geothermal water to the system. The net power output in the plant is calculated to be $9543 \mathrm{~kW}$. Using the exergy change of geothermal water is taken to be as the exergy input to the cycle. The exergy efficiency of the plant can be evaluated as $47.35 \%$ for the binary power plant.

Exergy destructions of the components of the Dore II binary geothermal power plant are given in Figure 2. The most destructive components are air cooled condensers, representing $1621 \mathrm{~kW}$ and $1123 \mathrm{~kW}$ of the total exergy destruction in the cycle, respectively. The causes of exergy destruction in the plant include heat exchanger losses, turbine-pump losses, the exergy of the geothermal water reinjected, and the exergy of $n$ pentane lost in the air cooled condensers. For binary geothermal power plants using air as the cooling medium, the condenser temperature varies as the ambient air temperature fluctuates throughout the year and even throughout the day. As a result, the power output decreases by up to $50 \%$ from winter to summer with exergy destructions.

The total investment cost rates of the binary geothermal power plant components are given in Table 2 . The unit cost of the n-pentane is $3.5 \$ / \mathrm{kg}$ by taking LHV of n-pentane as $45,227 \mathrm{~kJ} / \mathrm{kg}$, the specific unit exergetic cost of the working fluid is calculated to be 77.30 \$/GJ [21]. The exergetic cost rate of the working fluid at the exit of pump is obtained as $26.80 \$ / \mathrm{h}$ by taking the data given in Tables 1 and 2 . The exergetic cost rates and the specific unit exergetic costs of the states are given in Table 1 referring to Figure 1. These values are calculated by solving the equations with developed by SPECO approach that results are listed in Table 3. The unit exergetic cost of production electricity in the plant is calculated to be $10.22 \$$ /GJ by SPECO approach. 


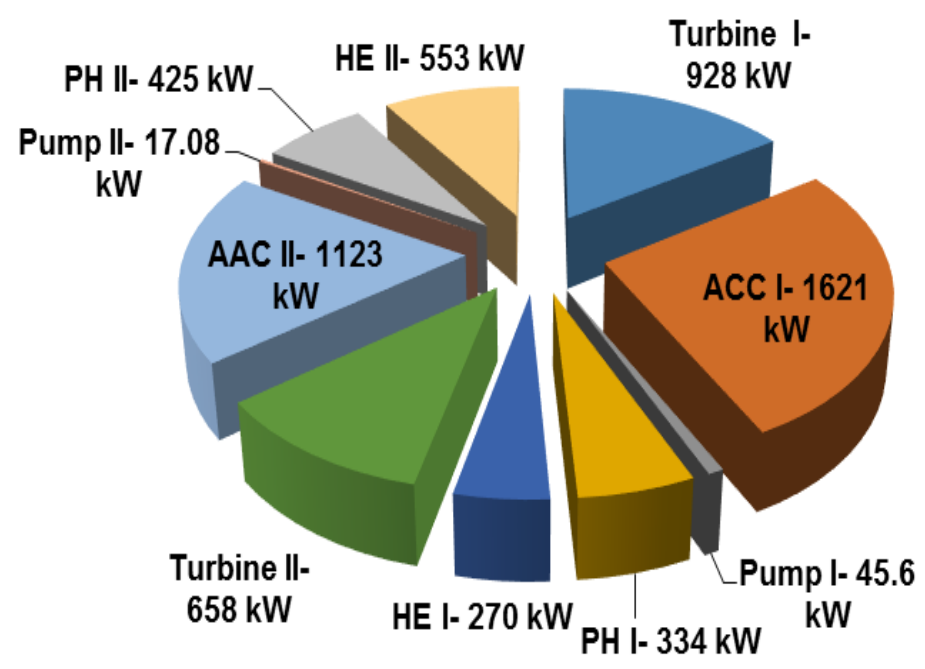

Figure 2. Exergy destructions in the components of Dore II binary power plant

As an important criterion in thermoeconomic assessment in component level is the exergy destruction cost rates. The values of destructions cost rates, under the real operating conditions (for $\mathrm{n}$ pentane as the working fluid), are presented in Figure 3 for the components of the plant. According to the Figure 3, air cooled condensers have higher values of exergy destruction cost rates compared to the other components.

The cost structure of the system can be obtained by applying Equation 12 to each component of the plant in MOPSA method. Thus, the unit exergetic cost of electricity produced in the plant is calculated to be $12.12 \$ / G J$ by this method. By using Equation 15, and the data provided by ref [21], capital recovery factor $(\mathrm{CRF})$ is obtained as 0.094 , and then the unit cost of the geothermal water $\left(c_{\text {geo }}\right)$ is calculated to be $4.56 \times 10^{-5}$ $\$ / \mathrm{kg}$. By taking the total sum of the capital and operating and maintenance costs as $384.503 \$ / \mathrm{h}$ in Table 2 , the unit exergetic cost of electricity produced in the plant is calculated to be 9.88 \$ GJ by Moran method.

The electricity production costs obtained for the existing binary geothermal power plant by SPECO, MOPSA and Moran methods are given in Table 4. The results indicated that the relative deviation in the production costs evaluated from SPECO and MOPSA methods is about 15.6\%. The relative deviation between SPECO and Moran methods is also about 3.6\%, but the relative deviation between MOPSA and Moran methods is about $18.6 \%$. The unit cost of electricity for the binary geothermal system is lower when Moran method is used.

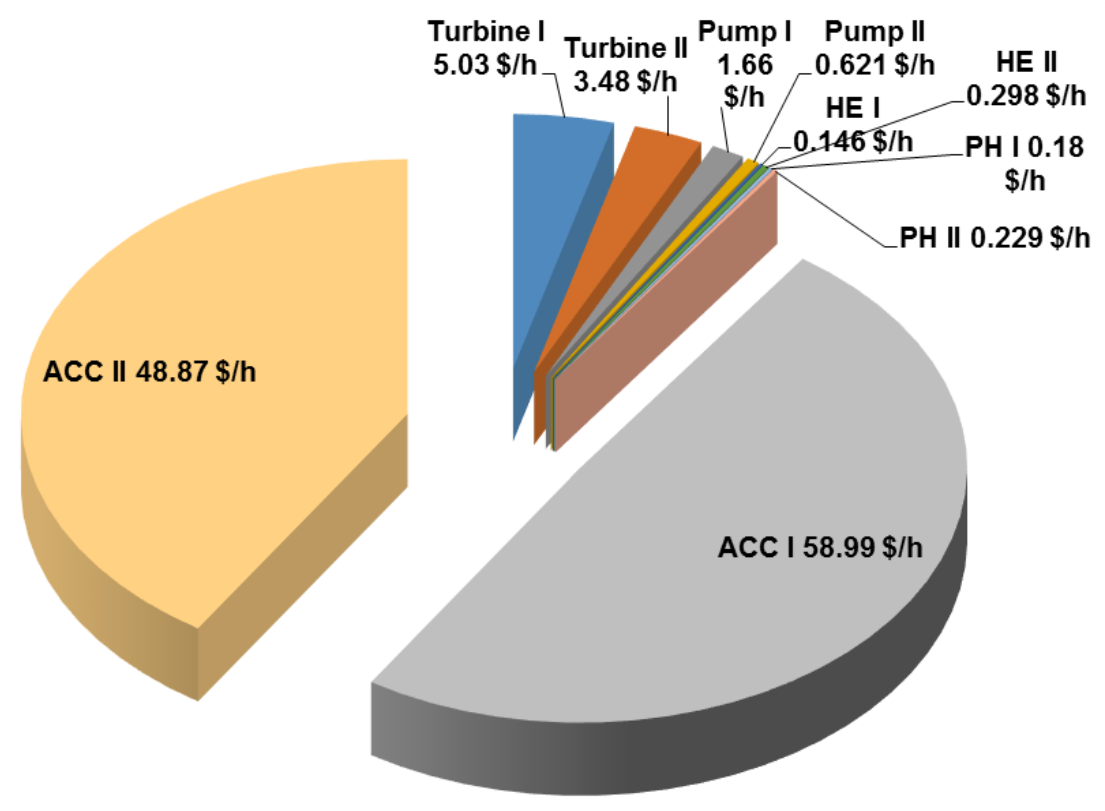

Figure 3. Exergy destruction cost rates of the Dora II binary geothermal power plant components 
Table 2. The cost rates associated with capital investment and operation and maintenance costs for the subcomponent of the plant [18]

\begin{tabular}{|c|c|c|c|c|}
\hline Components & PEC (\$) & $\dot{Z}_{k}^{I C}(\$ / \mathbf{h})$ & $\dot{Z}_{k}^{O M C}(\$ / \mathbf{h})$ & $\dot{Z}_{k}^{T}(\$ / \mathbf{h})$ \\
\hline Turbine-1 & $3,508,000$ & 139.458 & 26.563 & 166.021 \\
\hline Turbine-2 & $3,508,000$ & 139.458 & 26.563 & 166.021 \\
\hline Condenser-1 & 198,870 & 7.90 & 1.50 & 9.40 \\
\hline Condenser-2 & 198,870 & 7.90 & 1.50 & 9.40 \\
\hline Pump-1 & 76,000 & 3.021 & 0.575 & 3.596 \\
\hline Pump-2 & 76,000 & 3.021 & 0.575 & 3.596 \\
\hline Heat exchanger-1 & 65,940 & 2.621 & 0.50 & 3.120 \\
\hline Heat exchanger-2 & 65,940 & 2.621 & 0.50 & 3.120 \\
\hline Preheater-1 & 138,750 & 5.515 & 1.05 & 6.565 \\
\hline Preheater-2 & 138,750 & 5.515 & 1.05 & 6.565 \\
\hline Cooling pump & 95,000 & 3.776 & 0.719 & 4.495 \\
\hline Other plant equipments & 55,000 & 2.186 & 0.416 & 2.602 \\
\hline Total PEC & $8,125,120$ & 322.992 & 61.511 & 384.503 \\
\hline OMC & $513,183.3$ (\$/year) & & & \\
\hline
\end{tabular}

Table 3. The exergy flow rates, cost flow rates and the unit exergy costs associated with each stream of the plant by SPECO approach

\begin{tabular}{|c|c|c|c|}
\hline State & $\dot{E} x(\mathbf{k W})$ & $C(\$ / G J)$ & $\dot{C}(\$ / h)$ \\
\hline 1 & 10,054 & 1.505 & 54.49 \\
\hline 2 & 2569 & 1.505 & 13.92 \\
\hline 3 & 96.32 & 77.30 & 26.80 \\
\hline 4 & 292.1 & 37.40 & 39.33 \\
\hline 5 & 3213 & 4.12 & 47.68 \\
\hline 6 & 6615 & 1.471 & 35.03 \\
\hline 7 & 1542 & 1.471 & 8.167 \\
\hline 8 & 42.91 & 77.30 & 11.94 \\
\hline 9 & 114.7 & 45.60 & 18.82 \\
\hline 10 & 3209 & 2.361 & 27.28 \\
\hline 11 & 20,154 & 0.15 & $\begin{array}{l}10.18 \\
\end{array}$ \\
\hline 12 & 13,312 & 0.15 & 7.188 \\
\hline 13 & 4725 & 0.15 & 2.552 \\
\hline 14 & 1229 & 0.15 & 0.6637 \\
\hline 15 & 4725 & 0.15 & 2.552 \\
\hline 16 & 1431 & 0.15 & 0.7727 \\
\hline 17 & 1330 & 0.15 & 0.7182 \\
\hline 18 & 232.29 & 0.15 & 0.1254 \\
\hline 19 & 216.54 & 0.15 & 0.1169 \\
\hline 20 & 0 & 10.11 & 0 \\
\hline 21 & 847.2 & 6.77 & 20.64 \\
\hline 22 & 0 & 10.11 & 0 \\
\hline 23 & 606 & 4.85 & 10.58 \\
\hline$\dot{W}_{\text {turb.I}}$ & 6557 & 8.75 & 206.6 \\
\hline$\dot{W}_{t u r b H}$ & 4414 & 12.13 & 193 \\
\hline$\dot{W}_{\text {pump. }}$ & 241.4 & 10.11 & 8.932 \\
\hline$\dot{W}_{\text {pump.LI }}$ & 88.83 & 10.11 & 3.287 \\
\hline$\dot{W}_{\text {plant }}^{\text {pump }}$ & 9543 & 10.11 & 400 \\
\hline
\end{tabular}


The Moran method is simpler than the SPECO and MOPSA methods, but the result is worthy of the results of these two methods. Also the Moran method can be used only in one case and it is when the power plant produces only one product, but we can use the MOPSA and SPECO methods for power plants that produce more than one product. The SPECO method is simpler than MOPSA method and its result is also near to the result of the Moran method. Therefore, it can be selected as the best of the methods presented. Power output linearly increases with the geothermal water temperature as shown in Figure 4. Maximum power outputs are more sensitive at lower temperature than at higher temperatures because the thermodynamic efficiency of the cycle sharply decreases with temperature.

Table 4. The comparison of electricity production costs of the system for different methods

\begin{tabular}{|c|c|c|}
\hline Method & $c_{\text {electcity }}(\$ / \mathbf{G J})$ & $c_{\text {electcity }}(\mathbf{\$} / \mathbf{k W h})$ \\
\hline MOPSA & 12.12 & 0.0436 \\
\hline SPECO & 10.22 & 0.0368 \\
\hline Moran & 9.88 & 0.0355 \\
\hline
\end{tabular}

Some parametric studies are given below. The variations of the geothermal water temperature on the thermodynamic and economic parameters of the system have been investigated.

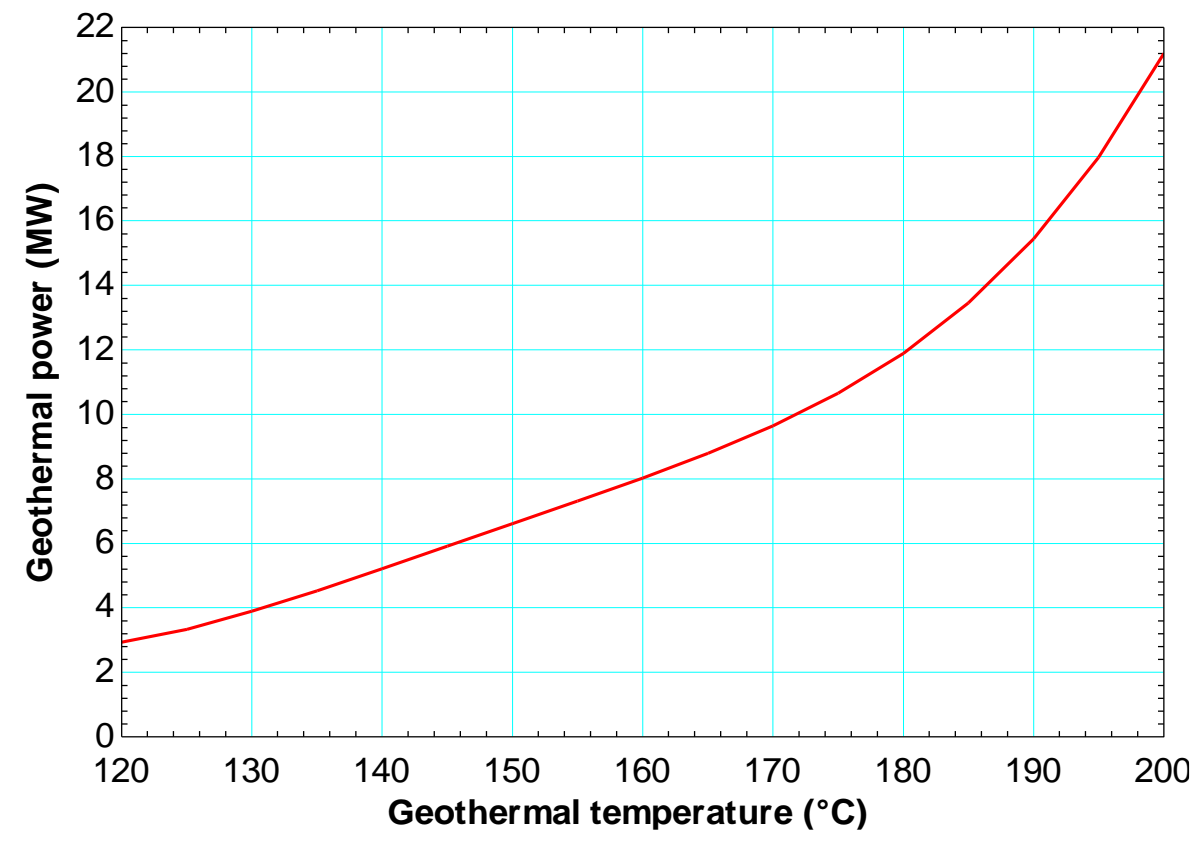

Figure 4. Exergy destruction cost rates of the Dora II binary geothermal power plant components

Figure 5 shows the variation of electricity production cost with respect to the different power outputs by SPECO, MOPSA and Moran methods. The mass flow rate and temperature of the geothermal water are the two important parameters in cost calculations and the change of the unit cost of electricity is crucially dependent on the temperature of the geothermal water.

Figure 6 shows the variation of electricity production cost with respect to the different geothermal water temperatures by three methods considered. As can be seen from the Figure 6, the production cost of electricity logarithmically decreases with the increase of geothermal water temperature. The reason is that more energy absorbed is obtained from the same geothermal water. 


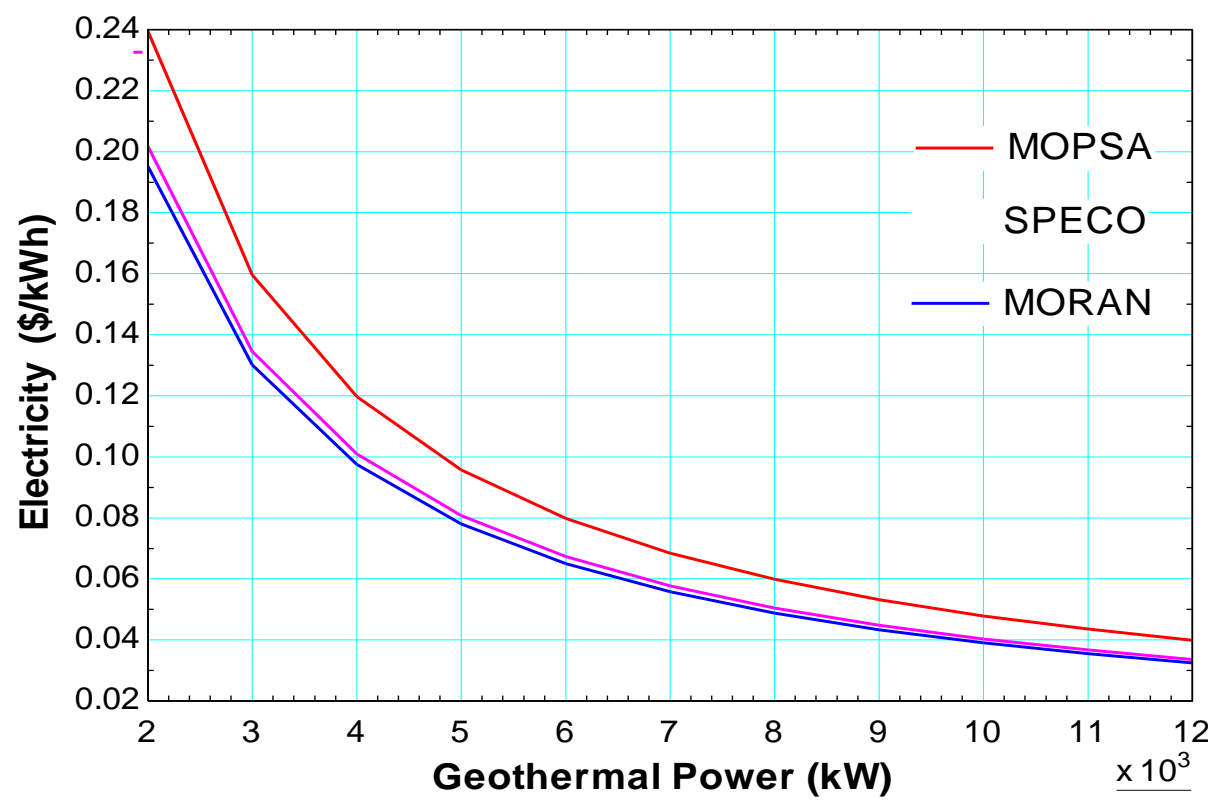

Figure 5. Exergy destruction cost rates of the Dora II binary geothermal power plant components

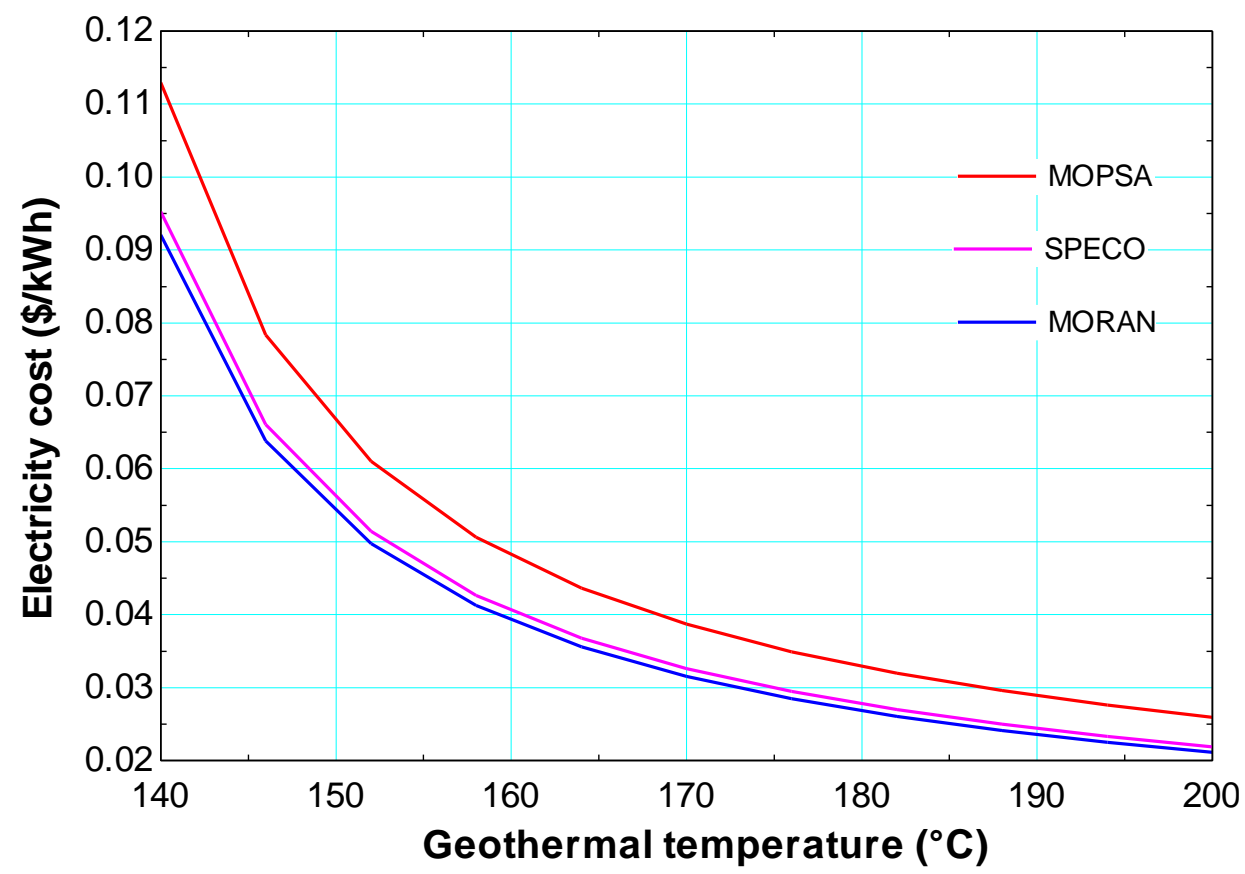

Figure 6. Variation of electricity production cost with respect to the different geothermal water temperatures by SPECO, MOPSA and Moran methods

\section{CONCLUDING REMARKS}

Energy system installation cost evaluation methods are based on cost allocation rules. In order to build up the cost formation of a thermal system, the general cost relations which link the flows of exergy inputs and outputs between system components must be obtained.

- In this study, the unit costs of the electricity produced by an existing binary geothermal power plant are compared in terms of three exergoeconomic methods. To the best of authors' knowledge, this study is the first one for the comparison of these well-known exergoconomic methodologies by using the actual operational data of an existing binary geothermal power plant. 
- Under these realistic conditions, exergy rate input of the plant is evaluated to be $20,150 \mathrm{~kW}$. The net power output in the plant is calculated to be $9543 \mathrm{~kW}$. The exergy efficiency of the plant can be evaluated as $47.35 \%$ for the binary power plant.

- The unit exergetic electricity production costs in the plant are calculated to be $0.0436 \$ / \mathrm{kWh}$ for MOPSA method, $0.0367 \$ / \mathrm{kWh}$ for SPECO method and $0.0355 \$ / \mathrm{kWh}$ for Moran method, respectively.

- If the methods are evaluated within themselves, the lowest cost is always the Moran method and the highest cost is the MOPSA method that is evaluated. The SPECO method gives a cost result between these two methods.

- According to the results of study, specific exergy costing (SPECO) method is the best suitable approach to forecast and determined the production of electricity cost by two level binary geothermal plants.

- The SPECO method is much simpler in terms of feasibility and observation for energy system operations. The Moran method approximation is very simple and assumed to be a unit system. So, the results are not exactly sensitive. Because, the system has been model according to the one inlet and one exit flows. The MOPSA method approximation is the most complicated. The method is considered chemical properties and different entropy definition of each stream. Therefore, the analysis is more complex for different flows and chemical plant systems. But there is no need too much detail for the basic thermal systems

\section{ACKNOWLEDGEMENT}

This study is sponsored by the he Scientific Research Projects Unit at the Afyon Kocatepe University (BAP) with project number 17. KARIYER.160. This support is greatly appreciated.

\section{NOMECLATURE}

c cost per exergy unit, \$/GJ

$C \quad$ cost associated with exergy flow, $\$$

CRF capital recovery factor

$\dot{C} \quad$ cost rate associated with exergy, $\$ / \mathrm{h}$

ex specific exergy, $\mathrm{kJ} / \mathrm{kg}$

$\dot{E} x \quad$ rate of exergy flow, $\mathrm{kW}$

$h \quad$ enthalpy, $\mathrm{kJ} / \mathrm{kg}$

HE heat exchanger

$i \quad$ interest rate, $\%$

LHV lower heating value, $\mathrm{kJ} / \mathrm{kg}$

LC levelized cost, $\$ / y r$

$\dot{m} \quad$ mass flow rate, $\mathrm{kg} / \mathrm{s}$

PEC purchased equipment cost, \$

PH preheater

$P W \quad$ Present worth

$P W F \quad$ Present worth factor

$s \quad$ entropy, $\mathrm{kJ} / \mathrm{kg} \mathrm{K}$

$S \quad$ Salvage value, $\$$

$T$ temperature, ${ }^{\circ} \mathrm{C}$

NGC non condensable gases

$\dot{W} \quad$ power, $\mathrm{kW}$

$\dot{Z}_{k} \quad$ capital cost rate unit, $\$ / \mathrm{h}$

$\eta \quad$ energy efficiency

$\varepsilon \quad$ exergy efficiency

$\tau \quad$ capacity factor of system

\$ United State Dollars, US\$

$0 \quad$ standard state 


$\begin{array}{ll}e & \text { exit state } \\ \text { geo } & \text { geothermal water } \\ i & \text { inlet state } \\ \text { in } & \text { inlet } \\ k & \text { system component } \\ x & \text { material stream } \\ \text { out } & \text { outlet } \\ \mathrm{q} & \text { heat } \\ \cdot & \text { time rate } \\ B Q & \text { Steam } \\ \mathrm{CHE} & \text { chemical } \\ \mathrm{CI} & \text { investment cost } \\ \mathrm{CC} & \text { carrying charges } \\ \mathrm{CHE} & \text { chemical } \\ m & \text { material } \\ \mathrm{OC} & \text { operation maintenance } \\ N & \text { operating period, year } \\ P & \text { mechanical } \\ T & \text { thermal } \\ W & \text { power }\end{array}$

\section{REFERENCES}

[1] Kanoglu, M., Yilmaz, C. (2013). Thermal Design of Alkaline Water Electrolysis Assisted by Combined Flash Binary Geothermal Power Plant. In ASME 2013 International Mechanical Engineering Congress and Exposition. American Society of Mechanical Engineers.

[2] Cengel, Y. A., Boles, M. A., (2015). Thermodynamics: an engineering approach, 8th edition.

[3] Yilmaz, C. (2017). Thermoeconomic modeling and optimization of a hydrogen production system using geothermal energy. Geothermics, 65, 32-43.

[4] Erkan, K., Holdmann, G., Benoit, W., Blackwell, D. (2008). Understanding the Chena Hot Springs, Alaska, geothermal system using temperature and pressure data from exploration boreholes. Geothermics, 37(6), 565585 .

[5] Coskun, A., Bolatturk, A., Kanoglu, M. (2014). Thermodynamic and economic analysis and optimization of power cycles for a medium temperature geothermal resource. Energy conversion and management, 78, 39-49.

[6] Ganjehsarabi, H., Gungor, A., Dincer, I. (2012). Exergetic performance analysis of Dora II geothermal power plant in Turkey. Energy, 46(1), 101-108.

[7] Zare, V. (2015). A comparative exergoeconomic analysis of different ORC configurations for binary geothermal power plants. Energy Conversion and Management, 105, 127-138.

[8] Yildirim, D., Ozgener, L. (2012). Thermodynamics and exergoeconomic analysis of geothermal power plants. Renewable and Sustainable Energy Reviews, 16(8), 6438-6454.

[9] Rašković, P., Guzović, Z., Cvetković, S. (2013). Performance analysis of electricity generation by the medium temperature geothermal resources: Velika Ciglena case study. Energy, 54, 11-31.

[10] Coskun, C., Oktay, Z., Dincer, I. (2011). Modified exergoeconomic modeling of geothermal power plants. Energy, 36(11), 6358-6366.

[11] http://enerjienstitusu.com/category/haber/yesil-enerji/jeotermal-enerji/

[12] Lazzaretto, A., Tsatsaronis, G. (2006). SPECO: a systematic and general methodology for calculating efficiencies and costs in thermal systems. Energy, 31(8), 1257-1289.

[13] Lazzaretto, A., Tsatsaronis, G. (2001). Comparison between SPECO and functional exergoeconomic approaches. In Proceedings of the ASME international mechanical engineering congress and exposition-IMECE23656.

[14] Kwak, H. Y., Kim, D. J., Jeon, J. S. (2003). Exergetic and thermoeconomic analyses of power plants. Energy, 28(4), 343-360.

[15] Moran, M. J. (1999). Fundamentals of exergy analysis and exergy-aided thermal systems design. In Thermodynamic Optimization of Complex Energy Systems (73-92). 
[16] Yildirim, D., Ozgener, L. (2012). Thermodynamics and exergoeconomic analysis of geothermal power plants. Renewable and Sustainable Energy Reviews, 16(8), 6438-6454.

[17] Kanoglu, M., Bolatturk, A. (2008). Performance and parametric investigation of a binary geothermal power plant by exergy. Renewable Energy, 33(11), 2366-2374.

[18] Bejan, A., Tsatsaronis, G. (1996). Thermal design and optimization. John Wiley and Sons.

[19] Dhillon, B. S. (2009). Life cycle costing for engineers. CRC Press.

[20] Dickson, M. H., Fanelli, M. (2013). Geothermal energy: utilization and technology. Routledge.

[21] Durmuş, T. (2017). Salavatlı Jeotermal Santralinin Ekserji Analizi (PhD dissertation). 